\title{
O perfil de cooperativas agropecuárias fornecedoras de alimentos para programas de segurança alimentar e nutricional
}

\author{
Joice Zagna Valent* \\ Leonardo Xavier da Silva**
}

\begin{abstract}
Resumo
As cooperativas agropecuárias facilitam a relação dos agricultores familiares com os mercados, possibilitam o acesso à informação e tecnologia, constroem estrutura física para o processamento de alimentos, fornecem assistência técnica e apoio logístico. Por isso, estas organizações colaboram com o progresso econômico, com a redução da pobreza e garantia de segurança alimentar. Por sua vez, as premissas das políticas de Segurança Alimentar e Nutricional (SAN) possuem similaridades com as cooperativas de agricultores familiares nas áreas de produção alimentar, ações de preservação ambiental, respeito à diversidade cultural, promoção da inclusão social e geração de renda. Assim, as cooperativas facilitam a participação de agricultores familiares no Programa de Aquisição de Alimentos (PAA) e no Programa Nacional de Alimentação Escolar (PNAE). Nesse contexto, o trabalho caracterizou cooperativas agropecuárias que fornecem alimentos para o PAA e o PNAE, no estado do Rio Grande do Sul, Brasil. Também foi explanado os desafios enfrentados para participar dos referidos programas. Para tanto, foi realizada uma pesquisa descritiva com 43 cooperativas que responderam a um questionário semiestruturado. A produção de alimentos é diversificada e para 25 cooperativas o PAA e o PNAE são os principais canais de venda da produção. As cooperativas precisam ampliar seus mercados para que não haja dependência total, pois, apesar da importância desses programas na manutenção das referidas organizações, eles podem não ser permanentes.
\end{abstract}

Palavras-chave: Cooperativismo, Agricultura Familiar, Comercialização, Mercados Institucionais.

\section{The profile of agricultural cooperatives that supply food for food and nutrition security programs}

\begin{abstract}
Agricultural cooperatives facilitate the relationship between family farmers and markets, enable access to information and technology, build a physical structure for food processing, provide technical assistance and logistical support. For this reason, these organizations collaborate with economic progress, reducing poverty and ensure food security. In turn, the premises of the Food and Nutrition Security policies have similarities with family farmers cooperatives in the areas of food production, environmental preservation actions, respect for cultural diversity, promotion of social inclusion and income generation. Thus, cooperatives facilitate the participation of family farmers in the Food Acquisition Program (PAA) and in the National School Feeding Program (PNAE). In this context, the work characterized agricultural cooperatives that provide food for PAA and PNAE, in the state of Rio Grande do Sul, Brazil. The challenges faced in participating in these programs were also explained. For this purpose, a descriptive research was done with 43 cooperatives that answered a semi-structured questionnaire. Food production is diversified and for 25 cooperatives, PAA and PNAE are the main sales channels for production. Cooperatives need to expand their markets to that there is no total dependence, because, despite the importance of these programs in maintaining these organizations, they may not be permanent.
\end{abstract}

Keywords: Cooperativism, Family Farming, Marketing, Institutional Markets.

\footnotetext{
*Doutorado em Agronegócios (UFRGS). Servidora Pública, Secretaria de Educação do Estado do Rio Grande do Sul. E-mail: jzvalent@gmail.com

** Doutorado em Economia (UFRGS). Professor do Programa de Pós-Graduação em Desenvolvimento Rural (PPGDR) e do Programa de Pós-Graduação em Agronegócios (PPGA) da Universidade Federal do Rio Grande do Sul (UFRGS).

E-mail: leonardo.xavier@ufrgs.br
} 


\section{Introdução}

Com uma abordagem contemporânea, o cooperativismo agropecuário torna-se fundamental para a promoção do desenvolvimento sustentável e para a competição em um mercado global. Nessa perspectiva, a cooperação significa a busca pela melhoria da qualidade de vida do produtor, tanto em termo social, quanto econômico e ambiental (RIBEIRO; NASCIMENTO; SILVA, 2013). As cooperativas agropecuárias têm papel de destaque no processo de desenvolvimento econômico das comunidades onde estão inseridas. Para a FAO (2012a), devese incentivar este tipo de organização produtiva, essencial para a segurança alimentar e a redução da pobreza, porque além de fornecer alimentos, as cooperativas contribuem para a inclusão de pequenos agricultores nas cadeias agrícolas de valor.

Nesse contexto, em 2012, ano internacional do cooperativismo, algumas metas foram atribuídas a estas organizações coletivas. Entre essas metas estão a contribuição para o progresso econômico, para a redução da pobreza e garantia de segurança alimentar. Isso ocorre quando as cooperativas oferecem oportunidades de mercado ao pequeno produtor, possibilitam acesso à informação, tecnologia, inovação e serviços de extensão rural. Essas organizações também podem proporcionar capacitações de gestão das propriedades e dos recursos naturais (FAO, 2012b).

Para Peraci e Bittencourt (2010), as cooperativas são formas de melhorar as relações com o mercado, de usufruir de políticas públicas ${ }^{1}$ e das diversas estruturas de apoio, como maquinários e espaços físicos, por exemplo. Dessa forma, as cooperativas podem ser organizações de negócios eficientes para promover o desenvolvimento rural ${ }^{2}$ e contribuir com a Segurança Alimentar e Nutricional - SAN (CHAGWIZA; MURADIAN; RUBEN, 2016).

Os programas de SAN tratados nesse trabalho são o Programa de Aquisição de Alimentos (PAA) e o Programa Nacional de Alimentação Escolar (PNAE). É possível observar que estes programas possuem similaridades com o cooperativismo agropecuário (principalmente quando

\footnotetext{
${ }^{1}$ Elaboradas a partir das crenças comuns e de representações de mundo de um conjunto de atores (públicos e privados). Estas crenças e representações definem a maneira como os agentes percebem os problemas públicos e concebem respostas e soluções aos mesmos (GRISA, 2012; FOUILLEUX, 2011).

${ }^{2}$ A partir da década de 1990 passou a ganhar espaço no Brasil, com discussões influenciadas pelas transformações sociais, políticas e econômicas que se operaram no âmbito do Estado, dos atores da sociedade civil e nos enfoques analíticos dos estudiosos e analistas (SCHNEIDER, 2010).
} 
se trata de cooperativas de agricultores familiares ${ }^{3}$ ). Os dois temas têm aspectos como: produção alimentar, respeito à diversidade cultural, ações de preservação ambiental e da saúde, promoção da inclusão social e geração de renda (GHIZZONI, 2016). Nesse contexto, o problema de pesquisa foi o seguinte: qual é o perfil de cooperativas agropecuárias fornecedoras de alimentos para o PAA e o PNAE? Consequentemente, o objetivo geral foi caracterizar as cooperativas que fornecem alimentos para o PAA e o PNAE. Já os objetivos específicos foram conhecer a estrutura das cooperativas, a organização da produção, os produtos fornecidos, os canais de comercialização dessas organizações (além do PAA e do PNAE) e, ainda, entender os desafios enfrentados para participar dos referidos programas.

O texto inicia com a introdução do tema, explanação do problema e dos objetivos. Em seguida, apresenta-se o referencial teórico, com os conceitos que estruturam o trabalho. Após são explicados os procedimentos metodológicos e os resultados e discussão. Para finalizar são expostas as considerações finais e referências utilizadas na construção deste trabalho.

Ressalta-se que este artigo faz parte de uma Tese de Doutorado apresentada ao curso de Pós-Graduação em Agronegócios, da Universidade Federal do Rio Grande do Sul, em dezembro de 2019.

\section{Referencial Teórico}

As cooperativas agropecuárias e a SAN possuem intersetorialidade. Tal afirmação encontra legitimidade no fato de que muitos agricultores familiares formam cooperativas para fornecer alimentos aos programas de políticas públicas, como o PAA e o PNAE. Em documentos da FAO relata-se a importância que as cooperativas têm no ambiente onde estão inseridas. Tal afirmação inclui produção sustentável e inserção na comunidade, por meio da geração de emprego e distribuição de renda. Então, os preceitos do cooperativismo agropecuário vão ao encontro dos princípios de SAN.

\footnotetext{
${ }^{3}$ São cooperativas formadas apenas por agricultores que cumprem os requisitos da Lei 11.326/06 (BRASIL, 2006a). Para ser considerada uma cooperativa de agricultura familiar é necessário ter $60 \%$ dos cooperados com DAP física.
} 


\subsection{Cooperativismo Agropecuário}

As cooperativas agropecuárias são uma forma de organização social dos agricultores, um meio de realizar transações comerciais e geradoras de emprego. Consequentemente colaboram na distribuição de renda mais justa, onde um possível resultado é a redução da pobreza. Por isso, são promotoras do desenvolvimento rural (ALTMAN, 2015). O cooperativismo agropecuário não tem legislação específica, ele está subjugado à Lei 5.764 de 1971. Esta define a política nacional do cooperativismo, o regime jurídico das sociedades cooperativas e seus princípios. Estudiosos da área cooperativista conferem ao cooperativismo agropecuário a responsabilidade de proporcionar desenvolvimento sustentável, onde ao mesmo tempo tenha geração e aumento de renda, criação de emprego e preservação ambiental. Portanto, essas organizações também desempenham um importante papel nas políticas públicas de promoção da SAN.

A importância de estudar o cooperativismo agropecuário está na agregação de valor e na promoção do desenvolvimento rural. Para Büttenbender (2010), essa cooperação considera todas as práticas que ocorrem entre os diferentes níveis e elos da cadeia produtiva agrícola. Partindo deste conceito, Araújo (2003) afirma que as cooperativas agropecuárias têm forte influência na coordenação de cadeias produtivas. Essas organizações podem atuar como simples organizadoras dos produtos, como empresas absorvedoras da produção ou podem ser comercializadoras de insumos e produtos agropecuários. Em algumas situações, agem como empresas integradoras e, neste caso, exercem uma função forte de coordenação. Altman (2015) enfatiza que fazer parte de uma cooperativa oferece mais chance para os agricultores familiares apresentarem participação mais robusta na economia. Além disso, eles deveriam criar outras cooperativas como: fornecedores de insumos, produção de valor agregado e de crédito. Assim, podem acumular benefícios econômicos mais diretos ou revertê-los à cooperativa para fins de investimento.

As organizações cooperativas agropecuárias podem melhorar o acesso ao mercado e ajudar os agricultores a evitar os perigos associados com produtos perecíveis e demanda variável, por exemplo. Além disso, as cooperativas têm poder de negociação, de formação de preços, podem servir como um veículo para a difusão de tecnologias, oferecem prestação de serviços e facilitam a obtenção de alguns benefícios, como subsídios do governo e obtenção de créditos para financiamentos (CHAGWIZA; MURADIAN; RUBEN, 2016). Na mesma linha, Wilkinson (2008) relata que o poder de negociação admite uma forma orientada para nichos de mercado, 
adequados às agroindústrias locais de pequeno e médio portes. Então, para Revillion et al (2001), algumas cooperativas agropecuárias possuem canais próprios de comercialização. Esta estrutura de mercado permite que seus produtos sejam valorizados em função da cultura local, pois facilita o reconhecimento dos consumidores e, também, sua inserção social na comunidade. Nessa linha de raciocínio, Sykuta e Cook (2001) defendem que as cooperativas têm um papel de inclusão, quando um pequeno agricultor consegue comercializar seu excedente e passa a fazer parte de um novo grupo social.

Além dessas relações, os canais de comercialização para as cooperativas são as feiras, os pontos próprios de vendas, a oferta dos produtos para supermercados e os mercados institucionais ${ }^{4}$. Para Bialoskorski Neto (2000), independentemente da forma de comercialização, as cooperativas precisam conciliar a manutenção do bem-estar social aos cooperados com o desenvolvimento de arranjos que permitam o aproveitamento das oportunidades que o mercado oferece.

O cooperativismo representa importante instrumento na viabilização do acesso ao mercado. Para muitos agricultores familiares é a única forma de escoar a produção, pois facilita as negociações e os procedimentos burocráticos. Por conseguinte, essas organizações podem atuar como fator distribuidor de renda, gerador de empregos e arrecadação, promovendo a dinamização econômica dos municípios e territórios rurais (SILVA; SCHULTZ, 2017). Assim, observa-se a relevância do papel do desempenhado pelo cooperativismo para o fortalecimento da agricultura familiar. As cooperativas atuam como entidades intermediárias entre a produção da agricultura familiar e as políticas públicas de SAN, como o PAA e o PNAE (CUNHA, 2015).

\subsection{Segurança Alimentar e Nutricional}

A Lei Orgânica no 11.346 de 2006 estabelece a definição de SAN e sua abrangência. Para a referida Lei, a SAN consiste na realização do direito de todos ao acesso regular e permanente a alimentos de qualidade, em quantidade suficiente, sem comprometer o acesso a outras necessidades essenciais, tendo como base práticas alimentares promotoras de saúde que

\footnotetext{
${ }^{4}$ Política pública que envolve as três esferas governamentais (municipal, estadual e federal) e aproxima o consumo da produção de base familiar. O Programa de Aquisição de Alimentos (PAA) e o Programa Nacional de Alimentação Escolar (PNAE) são exemplos destas políticas (PAULA; KAMIMURA; SILVA, 2014)
} 
respeitem a diversidade cultural e que sejam ambiental, cultural, econômica e socialmente sustentáveis.

Para Sarmento (2012), os desafios da SAN centram-se em três áreas: mecanismos de governança da segurança alimentar mais adequados; incremento da produção agrícola familiar e, por último; o acesso às tecnologias socialmente adequadas e políticas de proteção social sustentáveis. Para Paula, Kamimura e Silva (2014) é preciso aprimorar os aspectos ligados à diversificação e às tecnologias usadas na produção de alimentos, com o objetivo de atender à demanda dos mercados institucionais. Magalhães, Burlandy e Frozi (2013) destacam que as políticas de SAN (PAA e PNAE, por exemplo) defendem a produção e comercialização de alimentos sustentáveis e apoiam organizações sociais equitativas. Nesse sentido, surgem os diferentes arranjos no meio rural, entre eles as cooperativas.

Há o incentivo estatal à organização da agricultura familiar em cooperativas, pois ela é propulsora do desenvolvimento rural brasileiro. Este incentivo acontece por meio de políticas públicas, como a ampliação dos recursos do Programa Nacional de Fortalecimento da Agricultura Familiar (PRONAF) e a criação de programas como o PAA e a reformulação do PNAE (FAO, 2014). Tanto o PAA quanto o PNAE têm seu âmbito de atuação, com legislações específicas para o atendimento dos requisitos exigidos. Estes requisitos vão desde a forma de cultivo dos alimentos (orgânica, agroecológica ou convencional) até o tipo de organização que deve fornecer. O PAA e o PNAE são as principais políticas públicas de inserção da produção da agricultura familiar em mercados institucionais, com vistas a resolver um problema histórico de inserção desse segmento nos mercados (MACHADO, 2016).

\subsubsection{Programa de Aquisição de Alimentos - PAA}

Esse programa foi instituído pelo artigo 19 da Lei no 10.696, de 02 de julho de 2003, no âmbito do PFZ. Esta Lei foi alterada pela Lei no 12.512, de 14 de outubro de 2011 e regulamentada por diversos Decretos. O Grupo Gestor do PAA (GGPAA) é o órgão colegiado responsável pelo regramento do PAA. Ele tem caráter deliberativo, sendo formado por representantes de diversos Ministérios. O GGPAA orienta e acompanha a execução do PAA, normatizando-o por meio de suas resoluções.

Conforme a Lei no 10.696, de 02 de julho de 2003 (BRASIL, 2003), os objetivos do PAA são: 
$\checkmark$ Incentivar a agricultura familiar, promovendo a sua inclusão econômica e social, com fomento à produção com sustentabilidade, ao processamento de alimentos e industrialização e à geração de renda;

$\checkmark$ Incentivar o consumo e a valorização dos alimentos produzidos pela agricultura familiar;

$\checkmark$ Promover o acesso à alimentação, em quantidade, qualidade e regularidade necessárias, das pessoas em situação de insegurança alimentar e nutricional, sob a perspectiva do DHAA;

$\checkmark$ Promover o abastecimento alimentar, que compreende as compras governamentais de alimentos, incluída a alimentação escolar;

$\checkmark$ Constituir estoques públicos de alimentos produzidos por agricultores familiares;

$\checkmark$ Apoiar a formação de estoques pelas cooperativas e demais organizações formais da agricultura familiar; e

$\checkmark$ Fortalecer circuitos locais e regionais e redes de comercialização.

A agricultura familiar obteve muitos avanços desde a criação do PAA, mas são as organizações de agricultores familiares, ou seja, as cooperativas que ocupam cada vez mais estes espaços de comercialização institucional (SILVA; SCHULTZ, 2017). A institucionalização dos instrumentos de gestão e estratégias de aplicação do PAA, consideram necessária a organização coletiva dos agricultores (LIMA, 2011). Paula, Kamimura e Silva (2014) explicam que as cooperativas facilitam a inserção dos produtos em supermercados, feiras, restaurantes e também nos mercados institucionais. Além disso, podem oferecer tecnologias apropriadas para a produção e industrialização de alimentos, favorecer o atendimento às exigências sanitárias e organizar a logística da produção.

Silva e Schultz (2017) observam que cooperativas menores e fragilizadas, com pequena inserção no mercado, o fornecimento para o PAA representou uma oportunidade de aprendizagem para os agricultores familiares e suas organizações. Esta aprendizagem está relacionada ao planejamento da oferta, à logística de fornecimento e a organização e manutenção da documentação. O PAA também estimulou o surgimento e a expansão de muitas cooperativas e associações. 


\subsubsection{Programa Nacional de Alimentação Escolar - PNAE}

O PNAE é a maior e mais antiga política pública na área de alimentação e nutrição do Brasil e um dos maiores programas de alimentação escolar do mundo. Por isso representa uma estratégia de SAN que se orienta pelos princípios do DHAA (FNDE, 2016). Esse programa é executado desde a década de 1930 e também é o mais antigo programa brasileiro de SAN. Durante sua evolução, várias transformações proporcionaram a aproximação da agricultura familiar e da comunidade escolar, esta como consumidora. Essa relação fortaleceu a construção da política em SAN no Brasil, sendo um de seus programas centrais (SILVA; ROCKETT; COELHODE-SOUZA, 2018).

Atualmente, o PNAE oferece alimentação escolar e ações de educação alimentar e nutricional a estudantes de todas as etapas da educação básica pública. Em 2015, por exemplo, o PNAE atingiu 41,5 milhões de estudantes regularmente matriculados. A Resolução no 26 de 2013 relata que o PNAE atende os alunos matriculados na educação básica das redes públicas federal, estadual, distrital e municipal de ensino. São considerados como integrantes das redes estadual, municipal e distrital os alunos cadastrados no Censo Escolar do ano anterior ao do atendimento e matriculados na:

I - Educação básica das entidades filantrópicas ou por elas mantidas, inclusive as de educação especial e confessionais;

II - Educação básica das entidades comunitárias, conveniadas com o poder público.

O FNDE é o responsável pela coordenação, pelo estabelecimento das normas gerais de planejamento, execução, controle, monitoramento e avaliação do PNAE, bem como pela transferência dos recursos financeiros às entidades executoras - Estados, Distrito Federal, Escolas Federais e Municípios - (BRASIL, 2013).

O PNAE contribui para a prática de hábitos alimentares saudáveis e o melhor desempenho dos estudantes durante o aprendizado. Por isso, o objetivo do programa é proporcionar um cardápio escolar que atenda às necessidades nutricionais dos alunos enquanto permanecem na escola (CONTI, 2009). O objetivo do PNAE é contribuir para o crescimento e o desenvolvimento biopsicossocial, a aprendizagem, o rendimento escolar e a formação de hábitos alimentares saudáveis dos alunos, por meio de ações de educação alimentar e nutricional e da oferta de refeições que cubram as suas necessidades nutricionais durante o período letivo (BRASIL, 2009). 
Para tanto, as diretrizes da alimentação escolar são: o emprego da alimentação saudável e adequada, com o uso de alimentos variados, seguros, que respeitem a cultura, as tradições e os hábitos alimentares saudáveis; a inclusão da educação alimentar e nutricional no processo de ensino e aprendizagem, na perspectiva da SAN; a universalidade do atendimento aos alunos matriculados na rede pública de educação básica; a participação da comunidade no controle social, no acompanhamento das ações realizadas pelos Estados, pelo Distrito Federal e pelos Municípios para garantir a oferta da alimentação escolar saudável e adequada; o direito à alimentação escolar, respeitando as diferenças biológicas entre idades e condições de saúde dos alunos que necessitem de atenção específica e aqueles que se encontram em vulnerabilidade social; e, por último, o apoio ao desenvolvimento sustentável, com incentivos para a aquisição de gêneros alimentícios diversificados, produzidos em âmbito local e preferencialmente pela agricultura familiar e pelos empreendedores familiares rurais, priorizando as comunidades tradicionais indígenas e de remanescentes de quilombos. De acordo com a última diretriz referida e com o artigo 14 da Lei 11.947, a Lei da Alimentação Escolar abriu um novo mercado para os produtores citados, determinando que, no mínimo $30 \%$ dos recursos repassados pelo FNDE, para a alimentação nas escolas brasileiras, fossem destinados à compra de seus produtos (BRASIL, 2009).

\section{Procedimentos metodológicos}

Em decorrência de seu objetivo geral, esta pesquisa foi classificada como descritiva. Para Cervo e Bervian (2002), a pesquisa descritiva observa, registra, analisa e correlaciona fatos ou fenômenos (variáveis) sem manipulá-los. Esta pesquisa tem como finalidade principal a descrição das características de determinada população ou fenômeno. Para atingir o objetivo foram coletados dados primários, por meio de questionário semiestruturado. As perguntas do referido instrumento de pesquisa eram referentes aos objetivos das cooperativas, ao ano e motivos da formalização, ao número de cooperados e município de origem, ao selo ou registro dos produtos, ao tipo de agricultura, aos alimentos produzidos, a prestação de assistência técnica, aos canais de comercialização e aos desafios para a continuidade da comercialização no PAA e no PNAE.

A população alvo desta pesquisa são 74 cooperativas agropecuárias que comercializam alimentos no PAA e no PNAE e que são cadastradas na EMATER/RS, conforme atualização 
cadastral no ano de 2018 (EMATER/RS, 2018). Essas organizações são distribuídas pelas Unidades de Cooperativismo no Estado do Rio Grande do Sul, de acordo com a figura 1:

Figura 1: Unidades de Cooperativismo da EMATER/RS.

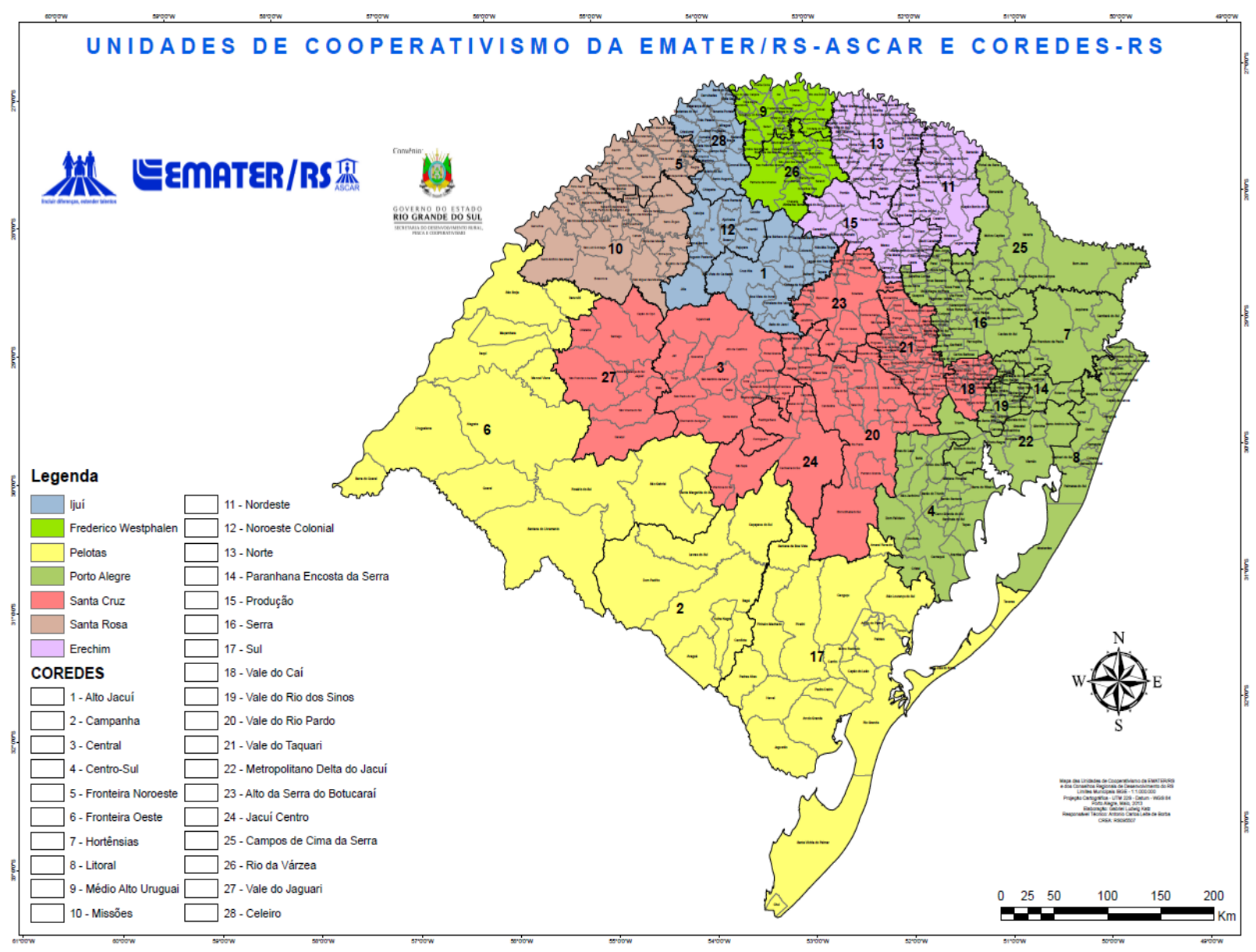

Fonte: EMATER/RS (2018).

A categoria de amostra utilizada foi a probabilística do tipo aleatória simples. A amostragem probabilística aleatória simples garante igual chance para todos os elementos participarem da amostra (MARCONI; LAKATOS, 2010). Então, as 74 cooperativas que compõem a população tiveram a mesma chance de participar da amostra, pois os questionários foram enviados para todas, por endereço eletrônico, no mês de setembro de 2018.

Para definir a amostra, fez-se um cálculo online com nível de confiança de 95\% e margem de erro de $10 \%$, onde confirmou uma amostra mínima de 43 cooperativas (SURVEYMONKEY, 2018). Coincidentemente foi o número de cooperativas que respondeu o questionário. O retorno dos questionários enviados por e-mail ocorreu até fevereiro de 2019. Também foram realizados contatos telefônicos e houve a participação em reuniões regionais das Unidades de 
Cooperativismo (UCPs), onde representantes de todas as cooperativas deveriam estar presentes. A aplicação dos questionários nas reuniões foi entre os meses de outubro e dezembro de 2018.

As respostas das perguntas feitas nos questionários foram tabuladas no Excel 2016 para posterior análise. Esta é apresentada na próxima seção.

\section{Resultados e Discussão}

Nessa seção são apresentados os resultados e realizada a discussão conforme os autores do referencial teórico, descrevendo o perfil das cooperativas agropecuárias e caracterizando os seus canais de comercialização,

\subsection{Caracterização das Cooperativas}

A média de idade dos respondentes da pesquisa é 44 anos, sendo que a pessoa com mais idade tem 66 anos e a com menor idade tem 22 anos. Do total, 20 são do gênero feminino e 23 do gênero masculino. As pessoas que se dispuseram a participar da pesquisa são: dezoito 18 presidentes, dois vice-presidentes, dois diretores, nove gerentes, um tesoureiro, um secretário, três assistentes administrativos, um coordenador de compras e seis cooperados.

Do total de respondentes, 18 possuem curso superior, três são pós-graduados e três pessoas têm graduação incompleta. Já, cinco têm curso de nível técnico, sete possuem ensino médio completo e dois com ensino médio incompleto. Ainda, duas pessoas detêm ensino fundamental completo e três incompleto.

As cooperativas estão distribuídas por vários municípios das UCPs da EMATER/RS, são elas: Antônio Padro, Eldorado do Sul, Osório, Sertão Santana, Caxias do Sul, Porto Alegre, Garibaldi, Viamão (duas cooperativas), Dom Feliciano, Três Cachoeiras, Camaquã, Pelotas, Turuçu, São José do Norte, Santiago, Santa Cruz do Sul (duas cooperativas), Vera Cruz, Ivorá, São Francisco de Assis, Santa Rosa, Três de Maio, Roque Gonzales, São Paulo das Missões, São Luiz Gonzaga, Cerro Largo, São Miguel das Missões, Santo Cristo, Horizontina, Campina das Missões, Sarandi, Frederico Westphalen, Getúlio Vargas (duas cooperativas), Erechim (três cooperativas), Passo Fundo, Tapejara, Aratiba, Lagoa Vermelha e Sananduva.

O total de cooperados nas 43 cooperativas é de 8.762 pessoas. A Cooperativa que possui mais associados soma 1.482 cooperados e a que tem menos reúne 26 cooperados, resultando na 
média de 204 associados por cooperativa. O gráfico 1 mostra o ano de formalização das cooperativas estudadas.

Gráfico 1: Ano de formalização das cooperativas pesquisadas

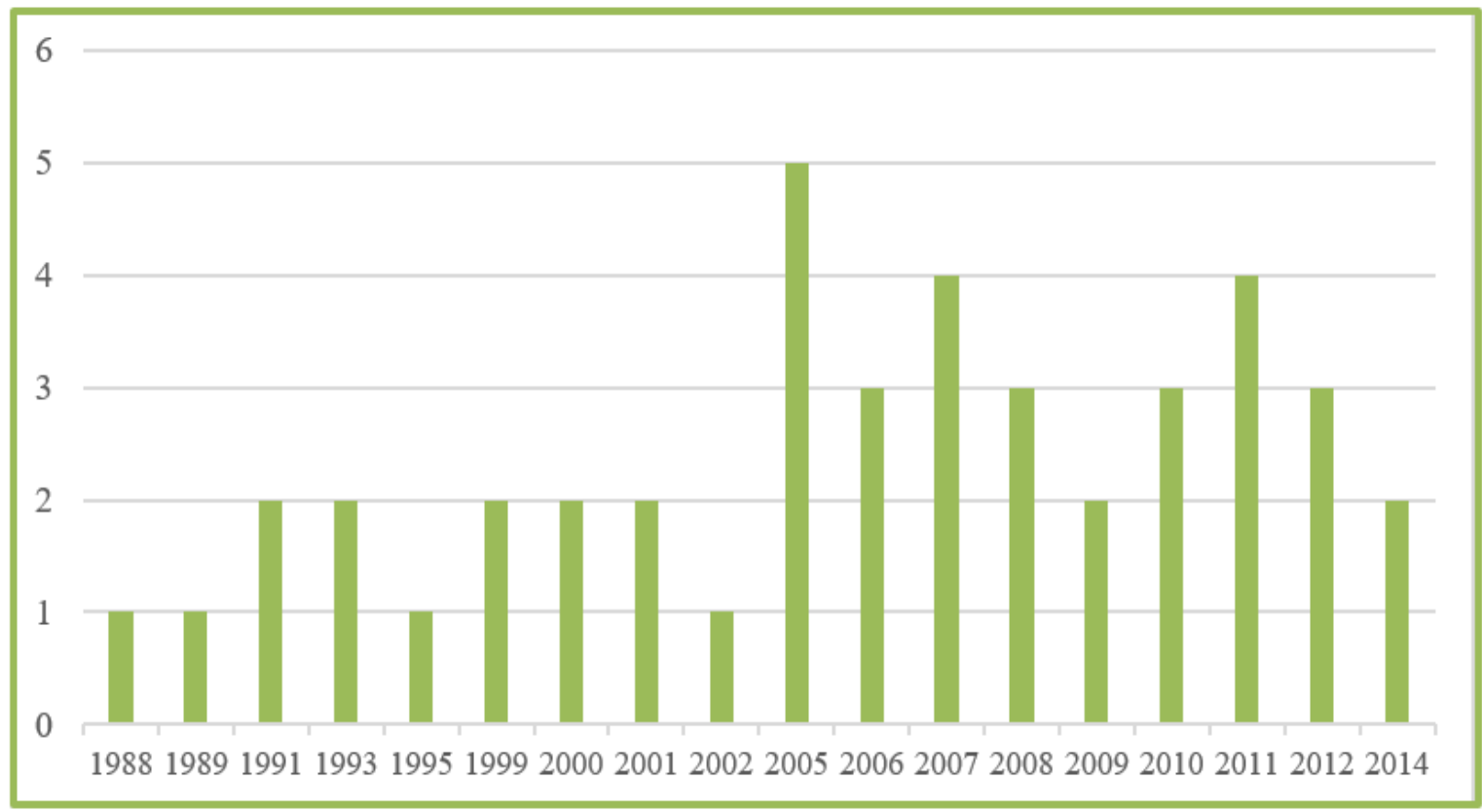

Fonte: dados da pesquisa (2019).

Percebe-se que 29 cooperativas foram criadas após 2003, quando houve forte apoio ao desenvolvimento de políticas públicas de SAN pelo governo federal. Isso demonstra que foram estimuladas pelas oportunidades oferecidas, principalmente, pelo PAA e pelo PNAE. Sobre os motivos que levaram a formação das cooperativas, 17 delas afirmaram que ocorreu a formalização, principalmente, para participar do PAA e do PNAE. Já 16 cooperativas relataram que para facilitar a comercialização de seus produtos em feiras, em supermercados, restaurantes, ou até mesmo para o PAA e o PNAE decidiram pela formalização. Ainda, quatro cooperativas disseram que a intenção inicial era promover a diversificação da produção. Outras respostas que apareceram com como segundo ou terceiro motivo para a legalização foram: obter financiamentos, promover saúde, praticar agricultura ecológica, ampliar a venda da produção, agroindustrializar o processamento de alimentos, facilitar a organização jurídica e comercializar o excedente. As cooperativas formadas por agricultores do Movimento Sem Terra relataram que era necessário organizar a produção dos assentamentos em função do alto volume produzido.

Percebe-se que as cooperativas agropecuárias citadas se formalizaram, principalmente, para facilitar a comercialização dos seus produtos. O mercado gerado pelos PAA e PNAE tiveram 
relevância nessa ação. Com isso, houve maior distribuição de renda entre os agricultores e sob a análise de Altman (2015) é uma forma de promover o desenvolvimento rural.

Com a formalização, as cooperativas determinaram objetivos a serem seguidos. Ressaltase que algumas cooperativas possuem mais de um objetivo. No geral, os referidos propósitos são relacionados com:

$\checkmark$ A organização da produção;

$\checkmark$ Abertura de novos mercados;

$\checkmark$ Diversificação produtiva;

$\checkmark$ Defesa dos interesses econômicos dos associados;

$\checkmark$ Promoção da integração, da solidariedade e do crescimento social aos cooperados;

$\checkmark$ O fortalecimento da agricultura familiar;

$\checkmark$ A transição para agricultura agroecológica e orgânica.

Quando se fala em objetivos, cinco cooperativas citaram que o único objetivo é comercializar para o PAA e o PNAE, demonstrando dependência destes programas. Outras cooperativas que se formalizaram para atender esses programas de SAN, já expandiram a atuação para diferentes mercados.

Além de facilitar a comercialização em diferentes mercados, estas cooperativas também proporcionam diversificação, organizam os produtos, absorvem a produção até de outras cooperativas ou, ainda, produzem e comercializam insumos. Assim, demonstram uma função forte de coordenação (ARAÚJO, 2003).

Chagwiza, Muradian e Ruben (2016) atribuem as organizações cooperativas a difusão de tecnologias, a prestação de serviços e a facilidade na obtenção de alguns benefícios. Nesse sentido, muitas cooperativas adquiriram selos de certificação de seus produtos. Nove delas têm o Selo de Identificação da Participação da Agricultura Familiar (SIPAF), 12 fazem parte da Rede Ecovida de Agroecologia a Certificação Participativa (ECOVIDA), cinco têm o selo sabor gaúcho e duas o selo Organização Participativa de Avaliação da Conformidade (OPAC). Outras cooperativas ainda citaram que possuem certificação pelo Instituto de Mercado Ecológico (IMO) do Brasil, pela Auditoria World Quality Services (WQS ${ }^{5}$ ) e pelo Centro de Apoio e Promoção da Agroecologia. Uma organização cooperativa citou que o Sistema de Inspeção Municipal oferece um selo de certificação, outras duas cooperativas possuem selos municipais e três afirmaram que a marca

${ }^{5}$ Sigla da expressão em inglês "World Quality Services" que significa Serviços de Qualidade Mundial. COLÓQUIO - Revista do Desenvolvimento Regional - Faccat - Taquara/RS - v. 18, n. 1, jan./mar. 2021 180 
própria é garantia de qualidade. Uma cooperativa está em fase de obtenção do selo ECOVIDA e 16 ainda não possuem certificação. Ressalta-se que três cooperativas possuem três certificações diferentes e quatro organizações têm dois selos diferentes. Uma cooperativa não possui certificação, mas algumas unidades familiares são portadores de diferentes selos.

As certificações estão de acordo com o tipo de agricultura. As cooperativas apresentam agricultura orgânica, agroecológica e convencional. Das 43 organizações que responderam o questionário, 17 delas possuem somente agricultura convencional, duas exclusivamente orgânica, duas apenas agroecológica e cinco possuem os três tipos. As outras 17 cooperativas têm dois tipos de agricultura entre orgânica, agroecológica e convencional.

Quando se compara as premissas da Lei 11.346/06 com a prática convencional de alimentos, percebe-se que os 32 empreendimentos cooperativos que praticam este tipo de agricultura não estão de acordo com a Lei referida. Ela não impede este tipo de produção para os mercados institucionais, mas a preferência é pela produção de alimentos orgânicos e agroecológicos. Grisa e Schneider (2014) reiteram que a sustentabilidade ambiental faz parte das políticas públicas para agricultura familiar. Essa sustentabilidade está relacionada, principalmente, com a produção de alimentos para os programas de SAN. Nesse sentido, Magalhães, Burlandy e Frozi (2013) destacam que as políticas de SAN (PAA e PNAE, por exemplo) defendem a produção e comercialização de alimentos sustentáveis e apoiam organizações sociais equitativas. Assim, as cooperativas, que têm o PAA e o PNAE como principais canais de comercialização, precisam adotar práticas sustentáveis de produção para contemplar as premissas da SAN. Outros estudiosos da área cooperativista também conferem ao cooperativismo agropecuário a responsabilidade de preservação ambiental. Portanto, essas organizações também são responsáveis pela aplicação dos princípios das políticas públicas de promoção da SAN.

Com práticas sustentáveis e cumprindo as exigências do PAA e do PNAE, a diversidade de alimentos comercializados pelas cooperativas é grande. Os itens produzidos são frutas, sucos, legumes, verduras, biscoitos, massas, pães, doces, geleias, conservas, embutidos, produtos de origem animal, leites e derivados. Para tanto, as cooperativas recebem, além da EMATER/RS, assistência de várias entidades para a organização produtiva, o planejamento da propriedade de cada agricultor, o apoio técnico para o cultivo e a gestão de recursos. Essas outras organizações são: UNICAFES, SESCOOP, Secretarias Municipais da Agricultura, Sindicato dos Trabalhadores na Agricultura Familiar, Serviço Brasileiro de Apoio às Micro e Pequenas Empresas (SEBRAE), 
Empresa Brasileira de Pesquisa Agropecuária (EMBRAPA), Centro Ecológico e Centro de Apoio e Promoção da Agroecologia. Uma cooperativa possui uma contratada que atua na assistência técnica. Já outra cooperativa, composta por agricultores de assentamento, recebe orientações da Sociedade Cooperativa de Prestação de Serviços Técnicos em áreas de Reforma Agrária, a COPTEC.

\subsection{Canais de Comercialização das Cooperativas Agropecuárias}

As cooperativas estudadas neste trabalho facilitam a organização produtiva e administrativa dos agricultores, para que estes possam oferecer o que o mercado demanda em termos de volume, diversidade, qualidade e regularidade na oferta. Parte significativa das cooperativas atua como instrumento de agregação de valor, por meio da agroindustrialização da produção, outra parte exerce papel de intermediação na comercialização da produção dos cooperados. Ainda têm aquelas que oferecem serviços como, por exemplo: ponto de venda, fornecimento de insumos e prestação de serviços de assistência técnica (SILVA; SCHULTZ, 2017).

Nesse contexto, das 43 cooperativas pesquisadas, 26 relataram que possuem um calendário que orienta as atividades de produção e comercialização. Entre as ações para organização estão: planilhas de controle, cronograma conforme a entrega de cada pedido, produção conforme a sazonalidade dos alimentos, exigências previstas em contrato, divisão de produção entre os agricultores, produção conforme os alimentos demandados pela merenda escolar e a data de feiras.

Cunha (2015) ressalta que as cooperativas têm um papel de intermediação entre a produção da agricultura familiar e as políticas públicas de SAN. Assim, muitas cooperativas aproveitaram as políticas públicas de SAN no século XXI (século corrente), como a criação do PAA e a reformulação do PNAE, para formalizar sua existência. Assim, tornaram esses meios nos seus canais de comercialização mais importantes (Gráfico 2).

As feiras não representam a principal oportunidade de mercado, porém 28 cooperativas também vendem seus produtos em feiras, sendo que 18 destas organizações participam quatro ou mais vezes por mês desta forma de comercialização. O PAA e o PNAE são os principais canais de comercialização para 25 cooperativas, 11 afirmaram que o ponto próprio é meio mais importante para vender seus produtos e quatro cooperativas relataram que as feiras são os principais canais de comercialização. O circuito de comercialização da Rede Ecovida é o principal 
canal para uma cooperativa. Ressalta-se que a opção de comercialização para supermercados e centrais de abastecimentos foi citada por duas vezes como a primeira opção. As centrais de cooperativas, embora não sejam muitas, representam um movimento crescente e estratégico para o processo de comercialização. São também importantes para a estabilização de preços dos produtos agrícolas em nível regional (SILVA; SCHULTZ, 2017). As outras alternativas que representam oportunidade de venda para os produtos são: restaurantes, vizinhança e circuito de comercialização.

Gráfico 2: Canais de comercialização mais importantes das cooperativas agropecuárias

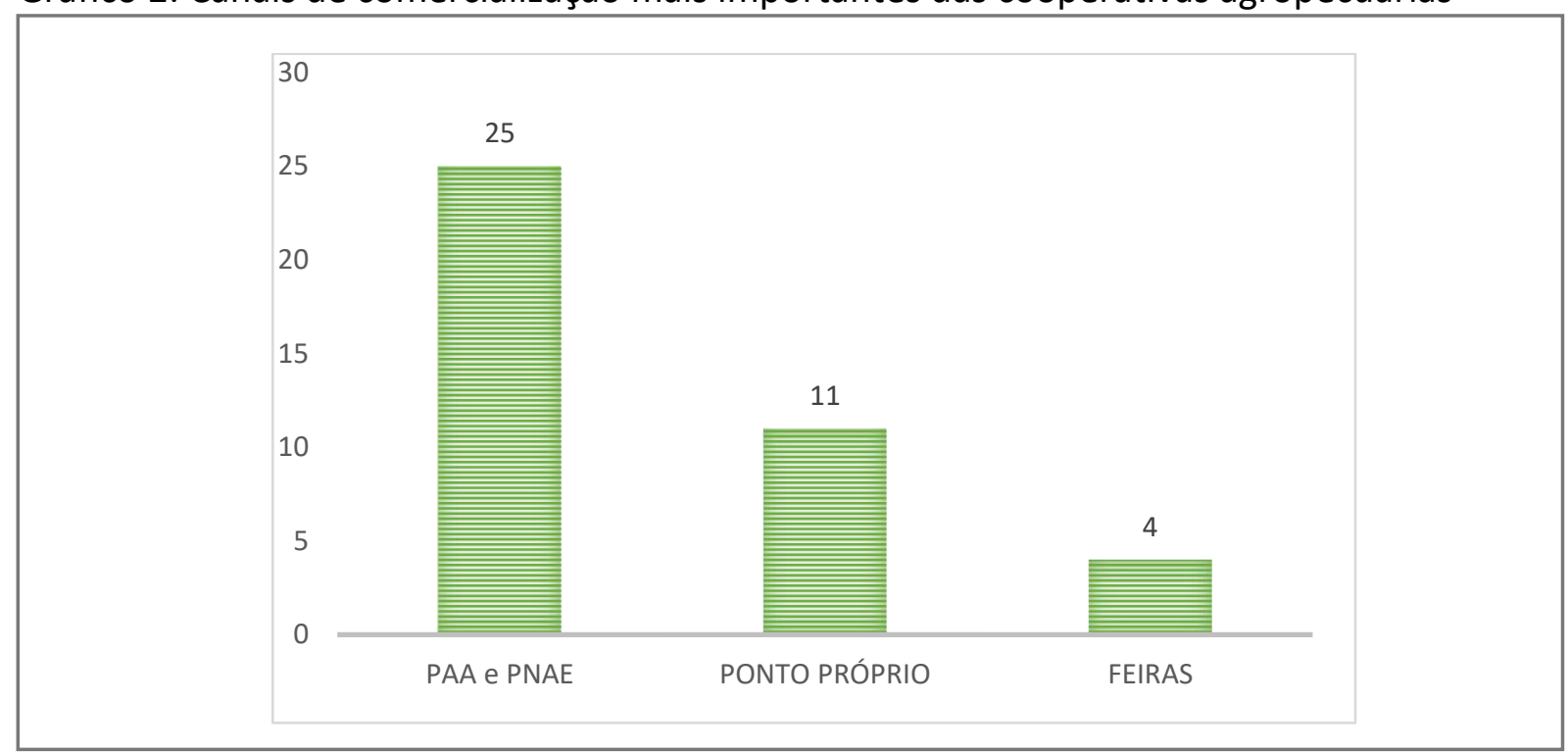

Fonte: dados da pesquisa (2019).

As feiras não representam a principal oportunidade de mercado, porém 28 cooperativas também vendem seus produtos em feiras, sendo que 18 destas organizações participam quatro ou mais vezes por mês desta forma de comercialização. O PAA e o PNAE são os principais canais de comercialização para 25 cooperativas, 11 afirmaram que o ponto próprio é meio mais importante para vender seus produtos e quatro cooperativas relataram que as feiras são os principais canais de comercialização. O circuito de comercialização da Rede Ecovida é o principal canal para uma cooperativa. Ressalta-se que a opção de comercialização para supermercados e centrais de abastecimentos foi citada por duas vezes como a primeira opção. As centrais de cooperativas, embora não sejam muitas, representam um movimento crescente e estratégico para o processo de comercialização. São também importantes para a estabilização de preços dos produtos agrícolas em nível regional (SILVA; SCHULTZ, 2017). As outras alternativas que 
representam oportunidade de venda para os produtos são: restaurantes, vizinhança e circuito de comercialização.

Pode-se explicar o alto número de cooperativas que aderiram à comercialização no PAA e no PNAE, porque estes programas são as principais políticas públicas de comercialização da produção da agricultura familiar, com vistas a resolver um problema histórico de inserção desse segmento nos mercados. Tanto o PAA quanto o PNAE têm seu âmbito de atuação, com legislações específicas para o atendimento dos requisitos exigidos. Estes requisitos vão desde a forma de cultivo dos alimentos (orgânica, agroecológica ou convencional) até o tipo de organização que deve fornecer. Isso também explica a formação de cooperativas (MACHADO, 2016).

É importante ressaltar que 40 cooperativas demonstraram interesse em aumentar os canais de comercialização das cooperativas. Deste número, 11 pretendem oferecer mais produtos para o PAA e o PNAE. Dez organizações coletivas querem estender a comercialização para restaurantes e oito apostam que a comercialização em feiras dará retorno financeiro para os cooperados. Ainda sete afirmam que a venda para supermercados e centrais de abastecimento pode ser um canal de venda promissor. Já duas cooperativas relatam que vender para vizinhos ajuda na complementação da renda, enquanto outras duas pretendem investir no próprio ponto de comercialização. Também foi citada a intenção de iniciar a venda online e uma loja especializada em produtos orgânicos. Para Silva e Schultz (2017), a combinação entre várias formas de comercialização é a estratégia efetiva adotada pelas cooperativas da agricultura familiar para escoamento da produção. Esses meios de comercialização acontecem em feiras livres, no varejo local ou regional, por meio do fornecimento de matérias primas para empresas e, em casos mais pontuais, via exportação.

A comercialização no PAA e no PNAE foi o primeiro acesso ao mercado para 21 cooperativas. As outras cooperativas já participavam de feiras, vendiam cestas para os vizinhos, forneciam para supermercados e oito cooperativas já possuíam ponto próprio de venda. Notase que esses dois programas de SAN ainda são mais importantes que o ponto próprio de comercialização para algumas cooperativas.

Conforme essa perspectiva, cooperativas agropecuárias necessitam ampliar seus espaços. Elas podem agir, tanto para assimilar novos valores, costumes e comportamentos originais do meio, como para consolidar sua identidade produtiva na própria região (STERNS; PETERSON, 2001). Neste sentido, contribuirão para a difusão de novos valores na comunidade e para acessar 
mercados de centros consumidores de maior porte (PELEGRINI; GAZOLLA, 2008). Ao combinar capacidade criativa territorial e identidade local - juntamente com aprendizagem e pesquisa uma unidade de produção cooperativa consolidará sua estrutura, adequando-a ao fortalecimento agrícola.

Mesmo o PAA e o PNAE sendo os canais mais significativos para a maioria das cooperativas pesquisadas, as cooperativas citaram os desafios enfrentados para a continuidade da comercialização nesses programas. Os desafios mencionados vão desde problemas rotineiros da produção até a continuidade dos programas pelo governo federal. A figura 2 mostra que a palavra "produtos" foi a mais citada pelos respondentes.

Figura 2: Palavras mais citadas nos desafios da comercialização no PAA e no PNAE

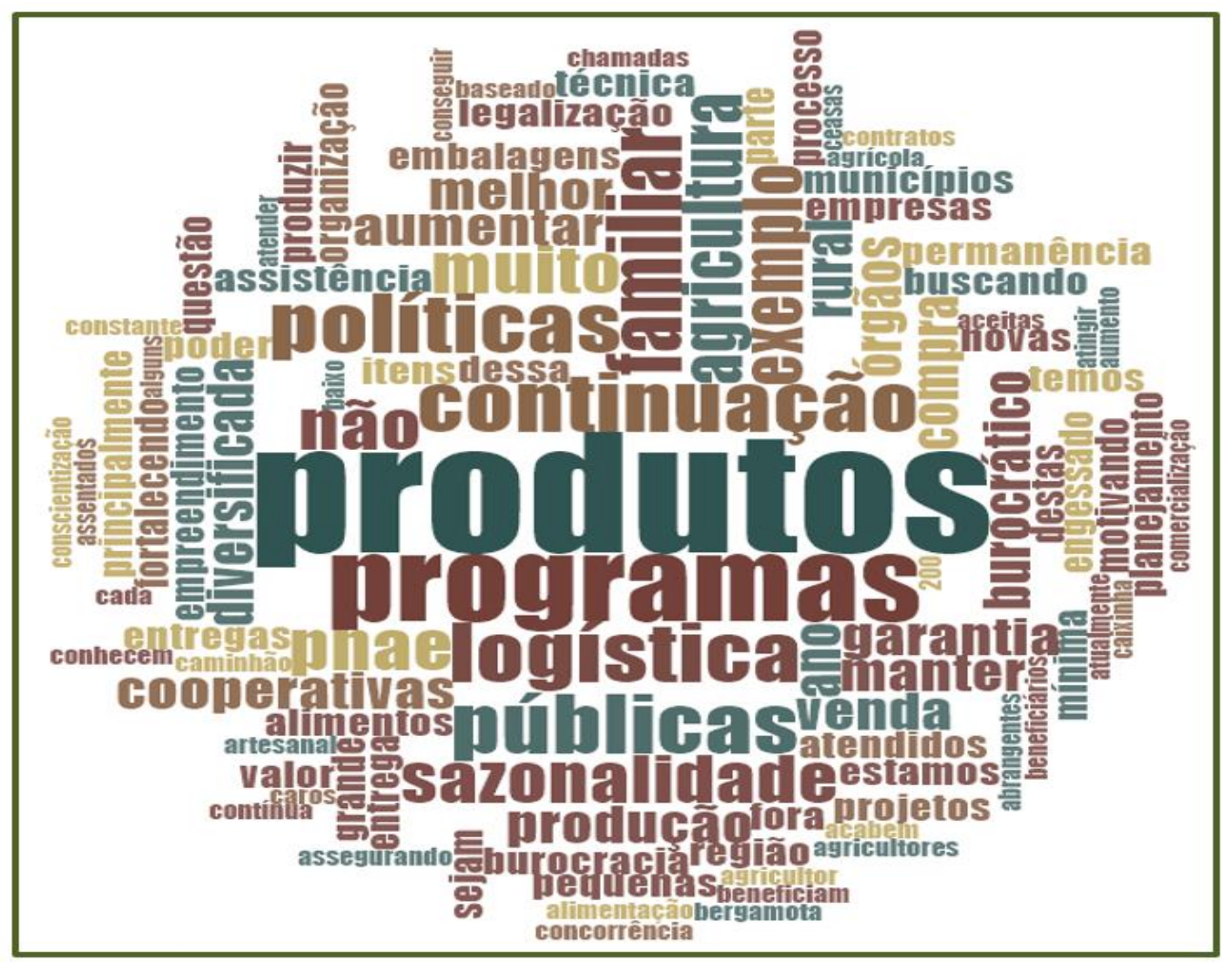

Fonte: dados da pesquisa (2019).

Muitos desafios citados estão envolvidos com os produtos. Entre as pessoas que responderam os questionários, 13 relataram que há uma grande preocupação em oferecer produtos diversificados, aumentar a produção e vendas para o PAA e o PNAE, além de atender a região onde estão inseridos. Para tanto, é preciso manter a disponibilidade constante, ao mesmo tempo que novos produtos são oferecidos. Para Paula, Kamimura e Silva (2014) é preciso ter diversificação para atender à demanda dos mercados institucionais. Outra questão alegada é a 
desvalorização da agricultura familiar e, consequentemente, de seus produtos. Os cooperados acreditam que a falta de conhecimento sobre essa categoria, inclusive por órgãos públicos, limita a comercialização dos produtos. A ideia é conseguir que os responsáveis pelas chamadas públicas elaborem um planejamento em conjunto com as cooperativas e baseado na sazonalidade dos produtos, onde os editais sejam disponibilizados com antecedência. Eles alegam que, muitas vezes, é requisitado frutas de inverno no verão e vice-versa, principalmente no PNAE. Para que a execução e prazos dos contratos sejam respeitados é preciso haver um planejamento flexível, pois produtos saudáveis e diversificados dependem da sazonalidade. Assim é possível organizar a produção. Percebe-se que quando se fala em "produtos" como um desafio para a continuidade da comercialização no PAA e no PNAE, o tema sazonalidade também é citado.

Outras palavras que se destacaram na figura 2 foram "continuação", "programas", "políticas", "públicas", "agricultura" e "familiar". Isso significa dizer que a continuação dos programas de SAN é compreendida como um desafio e também como um receio, pois, para as cooperativas de agricultura familiar não existem garantias referentes à manutenção do PAA e do PNAE pelos órgãos públicos. Doze respondentes citaram esse como o principal desafio enfrentado.

A palavra logística também se destacou como um desafio. As alegações foram de que o custo logístico é elevado e que é necessário investir em transporte para realizar as entregas. Uma cooperativa relatou que precisa, urgentemente, adquirir um caminhão para garantir as entregas para os programas. Também foram citados como desafios para a continuidade da comercialização no PAA e no PNAE as variações de preço (geralmente são baixos), barreiras sanitárias, as certificações, a aceitação das particularidades culturais de cada região, a permanência do agricultor na área rural e a busca constante pelo fortalecimento da agricultura familiar. Por outro lado, as organizações cooperativas sabem que precisam ter organização interna e buscar novos mercados.

É inegável que o PAA e o PNAE estimularam o surgimento e a expansão de muitas cooperativas e associações. Conforme Silva e Schultz (2017), com o PAA houve aprendizagem relacionada ao planejamento da oferta, à logística de fornecimento e a organização e manutenção da documentação, principalmente pelas cooperativas menores. Para Silva; Rockett; Coelho-de-Souza (2018), durante a evolução do PNAE várias transformações proporcionaram a aproximação da agricultura familiar e da comunidade escolar, fortalecendo a construção da política de SAN no Brasil. 
Além desses dois importantes canais de comercialização (PAA e PNAE), Chagwiza, Muradian e Ruben (2016) discutem que o desenvolvimento de cooperativas depende da sua capacidade de fornecer serviços de boa qualidade e de colocar em prática um sistema de governança inclusiva e eficiente.

\section{Considerações Finais}

Das 43 cooperativas pesquisadas, 29 formalizaram-se após 2003, com o surgimento do PAA e reformulação do PNAE, sendo que 17 destas organizações surgiram por causa da intenção em comercializar no PAA e no PNAE. As outras, apesar de conquistarem novos mercados, também têm nos mercados institucionais um importante canal de comercialização, tanto é que 25 cooperativas afirmaram que os referidos programas são os principais meios de escoamento da produção. As 14 cooperativas que existiam antes de 2003 comercializavam seus produtos em feiras, ponto próprio de venda, restaurantes e supermercados. Destaca-se a diversidade produtiva das cooperativas.

Devido à importância que o PAA e o PNAE representam para as cooperativas, faz-se necessário que esses programas sejam preservados e que as regras sejam respeitadas nos processos de compra e de abastecimento, tanto pelos executores quanto pelas referidas organizações. Ressalta-se que há uma forte dependência dos agricultores em relação ao PAA e ao PNAE. Então, as cooperativas precisam ampliar seus mercados com autonomia (expansão das feiras, por exemplo), pois deve haver uma garantia de venda dos produtos, caso o vínculo com os programas de SAN não seja permanente.

Agradecimento: à Coordenação de Aperfeiçoamento de Pessoal de Nível Superior (CAPES), pelo apoio financeiro.

\section{Referências}

ALTMAN, Morris. Cooperative organizations as an engine of equitable rural economic development. Journal of Co-operative Organization and Management, Amsterdam, v. 3, p. 1423, 2015.

ARAÚJO, Massilon J. Fundamentos de agronegócios. São Paulo: Atlas, 2003. 
BIALOSKORSKI NETO, Sigismundo. Agribusiness cooperativo. In: ZYLBERSZTAJN, D.; NEVES, M. F. (org.). Economia e gestão dos negócios agroalimentares. São Paulo: Pioneira, 2000. p. 235-253.

BRASIL. Lei no. 5.764, de 16 de dezembro de 1971. Define a Política Nacional de

Cooperativismo, institui o regime jurídico das sociedades cooperativas, e dá outras

providências. Diário Oficial da União: seção 1, Brasília, DF, p. 10354, 16 dez. 1971. Disponível em: http://www.planalto.gov.br/ccivil_03/leis/L5764.htm. Acesso em: 30 set. 2019.

BRASIL. Lei no. 10.696, de 2 de julho de 2003. Dispõe sobre a repactuação e o alongamento de dívidas oriundas de operações de crédito rural, e dá outras providências. Diário Oficial da União: seção 1, Brasília, DF, ano 140, n. 126, p. 1, 3 jul. 2003. Disponível em:

http://www.planalto.gov.br/ccivil_03/LEIS/2003/L10.696.htm. Acesso em: 5 dez. 2019.

BRASIL. Lei $\mathrm{n}$ - 11.346, de 15 de setembro de 2006. Cria o Sistema Nacional de Segurança Alimentar e Nutricional - SISAN com vistas em assegurar o direito humano à alimentação adequada e dá outras providências. Diário Oficial da União: seção 1, Brasília, DF, ano 143, n. 179, p. 1, 18 set. 2006b. Disponível em: http://www.planalto.gov.br/ccivil_03/_ato20042006/2006/lei/l11346.htm. Acesso em: 28 set. 2019.

BRASIL. Lei $\mathrm{n} 011.947$, de 16 de junho de 2009. Dispõe sobre o atendimento da alimentação escolar e do Programa Dinheiro Direto na Escola aos alunos da educação básica e dá outras providências. Diário Oficial da União: seção 1, Brasília, DF, ano 146, n. 113, p. 2, 17 jun. 2009. Disponível em: http://www.planalto.gov.br/ccivil_03/_ato2007-2010/2009/lei/l11947.htm. Acesso em: 20 out. 2019.

BRASIL. Lei $n=12.512$, de 14 de outubro de 2011. Institui o Programa de Apoio à Conservação Ambiental e o Programa de Fomento às Atividades Produtivas Rurais; altera as Leis no 10.696, de 2 de julho de 2003, 10.836, de 9 de janeiro de 2004, e 11.326, de 24 de julho de 2006. Diário Oficial da União: seção 1, Brasília, DF, ano 148, n. 199, p. 1, 17 out. 2011. Disponível em: http://www.planalto.gov.br/ccivil_03/_Ato2011-2014/2011/Lei/L12512.htm. Acesso em: 12 dez. 2019.

BRASIL. Ministério da Educação. Fundo Nacional de Desenvolvimento da Educação. Resolução no 26, de 17 de junho de 2013. Dispõe sobre o atendimento da alimentação escolar aos alunos da educação básica no âmbito do Programa Nacional de Alimentação Escolar - PNAE. Diário Oficial da União: seção 1, Brasília, DF, ano 150, n. 115, p. 7, 18 jun. 2013. Disponível em: https://www.fnde.gov.br/acesso-a-informacao/institucional/legislacao/item/4620resolu\%C3\%A7\%C3\%A3o-cd-fnde-n\%C2\%BA-26,-de-17-de-junho-de-2013. Acesso em: 10 nov. 2018.

BÜTTENBENDER, Pedro Luís. O agronegócio cooperativo. In: SPAREMBERGER, A.; BÜTTENBENDER, P. L.; ZAMBERLAN, L. (org.). Princípios de agronegócios: conceitos e estudos de casos. Ijuí: Unijuí, 2010. p. 71-98.

CERVO, Amado L.; BERVIAN, Pedro A. Metodologia científica. 5. ed. São Paulo: Prentice Hall, 2002.

CHAGWIZA, Clarietta; MURADIAN, Roldan; RUBEN, Ruerd. Cooperative membership and dairy performance among smallholders in Ethiopia. Food Policy, Guildford, v. 59, p. 165-173, 2016.

CONTI, Irio Luiz. Segurança alimentar e nutricional: noções básicas. Passo Fundo: IFIBE, 2009.

CUNHA, Wellington. A. Efeitos dos programas governamentais de aquisição de alimentos para a agricultura familiar no contexto local. 2015. 169 f. Dissertação (Mestrado em Administração) 
- Programa de Pós-Graduação em Administração, Universidade Federal de Viçosa, Viçosa, MG, 2015.

EMATER/RS - EMPRESA DE ASSISTÊNCIA TÉCNICA E EXTENSÃO RURAL. Programa de extensão cooperativa. Porto Alegre: EMATER/RS, 2018.

FAO - FOOD AND AGRICULTURE ORGANIZATION OF THE UNITED NATIONS. Good practices in building innovative rural institutions to increase food security. Rome: FAO, 2012a.

FAO - ORGANIZAÇÃO DAS NAÇÕES UNIDAS PARA A ALIMENTAÇÃO E A AGRICULTURA.

Cooperativas agrícolas alimentam o mundo. Roma: FAO, 2012b. Disponível em:

https://coin.fao.org/coin-static/cms/media/13/13455333629920/wfd2012_leaflet_pt_low.pdf. Acesso em: 10 jun. 2020.

FAO - ORGANIZAÇÃO DAS NAÇÕES UNIDAS PARA A ALIMENTAÇÃO E A AGRICULTURA. 0 estado de segurança alimentar e nutricional no Brasil: um retrato multidimensional: relatório 2014. Brasília, DF, 2014. Disponível em: https://fpabramo.org.br/acervosocial/wpcontent/uploads/sites/7/2017/08/334.pdf. Acesso em: 10 out. 2019.

FNDE - FUNDO NACIONAL DE DESENVOLVIMENTO DA EDUCAÇÃO. Histórico. Brasília, DF, 2016. Disponível em: https://www.fnde.gov.br/index.php/programas/pnae/pnae-sobre-oprograma/pnae-historico. Acesso em: 10 out. 2019.

GHIZZONI, Leila. Segurança e soberania alimentar. Porto Alegre: EMATER/RS, 2016. Disponível em: http://www.emater.tche.br/site/area-tecnica/inclusao-social-produtiva/seguranca-esoberania-alimentar.php\#.V_K4NdQrKt8. Acesso em: 13 jun. 2020.

GRISA, Cátia; SCHNEIDER, Sérgio. Três gerações de políticas públicas para a agricultura familiar e formas de interação entre sociedade e estado no Brasil. Revista de Economia e Sociologia Rural, Brasília, DF, v. 52, n. 1, p. 125-146, 2014.

LIMA, NEUSA P. B. O Programa de Aquisição de Alimentos (PAA) e seu impacto no processo de desenvolvimento socioprodutivo de famílias assentadas: estudo de caso no assentamento 17 de abril - Restinga/SP. 2011. 67 f. Trabalho de Conclusão de Curso (Graduação em Geografia Licenciatura e Bacharelado) - Curso de Geografia, Faculdade de Ciências e Tecnologia, Universidade Estadual Paulista, Presidente Prudente, 2011.

MACHADO, José A. Redes Sociais e Acesso a Políticas Públicas de Compra Governamental da Agricultura Familiar: um estudo de caso do município de Guaraciaba - MG. 2016. 99 f. Dissertação (Mestrado em Extensão Rural) - Programa de Pós-Graduação em Extensão Rural, Universidade Federal de Viçosa, Viçosa, MG, 2016.

MAGALHÃES, Rosana; BURLANDY, Luciene; FROZI, Daniela S. Programas de segurança alimentar e nutricional: experiências e aprendizados. In: ROCHA, Cecília; BURLANDY, Luciene; MAGALHÃES, Rosana (og). Segurança alimentar e nutricional: perspectivas, aprendizados e desafios para as políticas públicas. Rio de Janeiro: Fiocruz, 2013. p. 111-146.

MARCONI, Marina de Andrade; LAKATOS, Eva Maria. Técnicas de pesquisa: planejamento e execução de pesquisas, amostragens e técnicas de pesquisa, elaboração, análise e interpretação de dados. 7. ed. São Paulo: Atlas, 2010. 277p.

PAULA, M. M.; KAMIMURA, Q. P.; SILVA, J. L. G. Mercados Institucionais na agricultura familiar: dificuldades e desafios. Revista de Política Agrícola, Brasília, DF, v. 23, n. 1, p. 33-43, 2014. 
PELEGRINI, G.; GAZOLLA, M. A Agroindústria familiar no Rio Grande do Sul: limites e potencialidades a sua reprodução social. Frederico Westphalen, RS: Ed. da URI, 2008.

PERACl, Adoniram S.; BITTENCOURT, Gilson A. Agricultura familiar e os programas de garantia de preços no Brasil: o Programa de Aquisição de Alimentos (PAA). In: SILVA, José Graziano da; DEL GROSSI, Mauro E.; FRANÇA, Caio G. de. (org.). Fome Zero: a experiência brasileira. Brasília: Ministério do Desenvolvimento Agrário, 2010. p. 191-222.

REVILLION, J. P.; PADULA, A. D.; BRANDELLI, A. Estudo das variáveis relevantes na adoção da tecnologia de processamento UHT nas agroindústrias de laticínios no estado do Rio Grande do Sul. Revista do Instituto de Laticínios Cândido Tostes, Juiz de Fora, v. 56, n. 323, p. 3-12, 2001.

RIBEIRO, Kleber A.; NASCIMENTO, Deise C.; SILVA, Joelma F. B. Cooperativismo agropecuário e suas contribuições para o empoderamento dos agricultores familiares no submédio São Francisco: o caso da associação de produtores rurais do núcleo VI - Petrolina/PE. Teoria e Evidência Econômica, Passo Fundo, n. 40, p. 77-101, 2013.

SARMENTO, Francisco. A segurança alimentar e nutricional na comunidade dos países de língua portuguesa: trajetórias históricas na conformação de uma estratégia. In: LIMA, Sônia Centeno et al. Segurança alimentar e nutricional na comunidade dos países de língua portuguesa: desafios e perspectivas. Rio de Janeiro: Fiocruz, 2012.

SILVA, Camila M. V.; SCHULTZ, Glauco. Acesso a mercados e gestão de cooperativas da agricultura familiar no Brasil. Revista Espacios, Caracas, v. 38, n. 44, 2017.

SILVA, Taís M. da; ROCKETT, Fernanda C.; COELHO-DE-SOUZA, Gabriela. Desenvolvimento territorial e o programa nacional de alimentação escolar nos territórios rurais litoral e Campos de Cima da Serra no Rio Grande do Sul. Revista Brasileira de Gestão e Desenvolvimento Regional, Taubaté, v. 14, n. 1, p. 61-85, 2018.

STERNS, J. A.; PETERSON, H. C. The globalization of smaller agri-food firms: a decision-making framework tested through case research. International Food and Agribusiness Management Review, Stamford, v. 4, n. 2, p. 133-148, 2001.

SURVEYMONKEY. Calculadora de tamanho de amostra. San Mateo, 2018. Disponível em: https://pt.surveymonkey.com/mp/sample-size-calculator/. Acesso em: 10 maio 2018.

SYKUTA, Michael E.; COOK, Michael L. A new institutional economics approach to contracts and cooperatives. American Journal of Agricultural Economics, St. Paul, v. 83, n. 5, p.1273-1279, 2001.

WILKINSON, John. Mercados, redes e valores: o novo mundo da agricultura familiar. Porto Alegre: Editora da UFRGS, 2008. 